\title{
Modeling, Simulation and Analysis of Tapered Receiver Utilization in Solar Cycloidal Concentrating System for Enhancement of System Efficiency
}

\author{
Mohan Kulkarni ${ }^{1 *}$, Sunil Dingare ${ }^{2}$, Chandrakant Kulkarni ${ }^{3}$ \\ ${ }^{1}$ Department of Mechanical Engineering, MITSOE, MITADT University, Pune 412201, India \\ ${ }^{2}$ Department of Aerospace Engineering, MITSOE, MITADT University, Pune 412201, India \\ ${ }^{3}$ Department of Mechanical Engineering, ZCOE, SPP University, Pune 411041, India
}

Corresponding Author Email: mohankulkarni85@gmail.com

https://doi.org/10.18280/ijht.390225

Received: 5 September 2020

Accepted: 16 December 2020

\section{Keywords:}

solar energy, tapered receiver, solar cycloidal concentrator, receiver modeling, heat transfer simulation, CFD analysis

\begin{abstract}
This paper presents modeling, simulation and analysis of heat transfer and fluid flow in the tapered receiver used in solar cycloidal concentrating system which is a novel concept. The main objective of this paper is to analyze performance of solar cycloidal concentrating system by utilizing novel concept of tapered receiver for enhancement of system efficiency. This solar cycloidal concentrating system is used for testing purpose from Jan 20-April 20 in Pune city, India. The calibrated device Pyranometer is used to provide values of solar irradiance. Readings are taken daily after each one hour for the whole day. Modeling of the tapered receiver tube which is novelty of this research is done using SOLIDWORKS software. The governing equations of fluid flow and heat transfer in the system are solved by using ANSYS-CFX CFD software. The obtained results show efficiency increment and rise in temperature. Experimental results and analysis using software shows that using novel concept of tapered receiver, there is noticeable decrement in thermal losses as there is decrement in the area of receiver from inlet to outlet of receiver tube and hence increase in the efficiency is observed. The tapered receiver is designed in such a way that, the entire receiver tube of 20 feet is cut into a separate 20 pieces. Each piece is having $304.80 \mathrm{~mm}$ in long. Total 20 pieces are separately designed for manufacturing of taper receiver. For each piece cut of $0.9 \mathrm{~mm}$ from inlet to outlet is taken for OD as well as for ID using CNC machine. Tapered receiver was manufactured by using various operations which includes MS rod cutting, machining, welding, arrangement for sensor fitting at said location and end nozzles.
\end{abstract}

\section{INTRODUCTION}

Solar energy harvesting for heating the water has existence of application in commercial and household applications. Still there is a need to improve the system for the efficiency improvement of solar system and related improvement in temperature. The solar concentrating system which is used now a day where constant concentration ratio is used due to which there is a loss of heat. Hence there is a need to device such a concentrating system where these losses will reduce. In this paper an attempt is made for modeling, simulation, and analysis of tapered receiver utilization for solar cycloidal concentrating system for enhancing the efficiency and reducing the thermal losses.

Sukki et al. [1] presented a review on solar concentrator where it is mentioned that in spite of the advance designs achieved so far, there are still a lot of improvements that can be done especially on the concentrator and receiver designs. Padilla et al. [2] carried out one-dimensional heat transfer analysis of the parabolic trough solar receiver. The covered receiver kept under vacuum is used to avoid heat losses. The developed model is suitable for estimating the heat losses and collector efficiency. Meng et al. [3] presented a new type of concentrator viz. crossed compound parabolic concentrator (CCPC) through simulation for different geometric concentration ratio. It is found that the optical efficiency of
$\mathrm{CCPC}$ remained constant and high throughout the day. Horta et al. [4] has presented an optical simulation data rather than experimental procedure for optical characterization of the line focusing concentrators. Lof et al. [5] attempted to optimize focusing collector design by obtaining the ratio of the reflector area to the receiver area. The receiver in this case was flat and the effect of shadow was neglected. The receiver must be designed to absorb maximum energy and emit minimum energy; which is achieved by having a proper coating over the receiver surface as studied by Beucherie [6]. Mahdib et al. [7] presented the development of spherical solar collector with a cylindrical receiver. Intercept factor is proportional to the diameter of the receiver. Hence there is an energy increment intercepted by the receiver. For the enhancement in output there is a need to improve concentration ratio for continuously changing temperature of fluid and temperature of receiver [8]. Wirz et al. [9] studied the effect of system design on the average annual performance of the solar system and stated that the increase in receiver diameter leads to loss of system efficiency. Lüpfert et al. [10] in their study stated that the position of the receiver with respect to the focal line of the concentrator influence the intercept factor. Caron and Roger [11] proposed the model which can be used as model to design the receiver with heat transfer characteristic. Chen [12] Studied the energy distribution over the surface of the receiver to design an appropriate geometry of the receiver. Solar line 
concentrator system which is used in present day's solar systems is utilizing constant diameter receiver tube [13]. Fixed concentration ratio as shown in Figure 1 is having drawback of thermal loss and hence create an impact on lowering system efficiency. To overcome this problem, previously, some researchers put forth the concept of variable concentration ratio as shown in Figure 2 [14]. It is found that due to the use of solar system with stepped receiver tube, some increase in efficiency is observed. Along with it there are huge thermal and heat losses due to random variation in receiver tube diameter. Receivers may have covers transparent to solar radiation for reducing losses [15]. The problem with stepped receiver tube is overcame in a research by Kulkarni et al. [16] where instead of constant or stepped receiver tube, a tapered receiver tube is used. In this paper modeling, simulating and analysis of heat transfer and fluid flow for the tapered receiver used in solar cycloidal concentrating system is carried out. Climatic change will impact temperature and solar irradiance and therefore alters the output capacity of solar system. Hence it is observed that generally output of any solar system is based on local climatic conditions. The governing equations of fluid flow and heat transfer in the system are solved using ANSYSCFX CFD software.

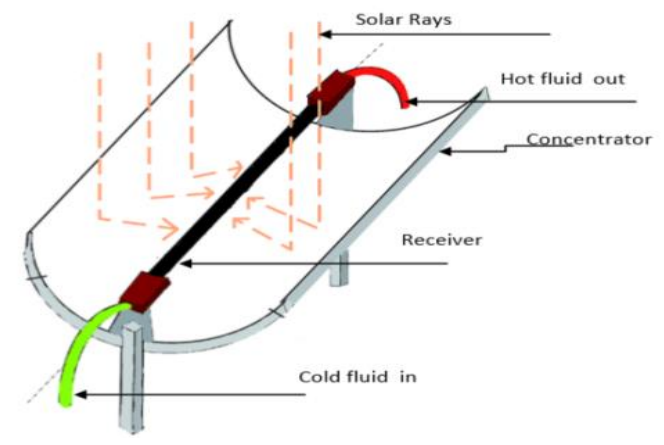

Figure 1. Solar system with constant diameter receiver [13]

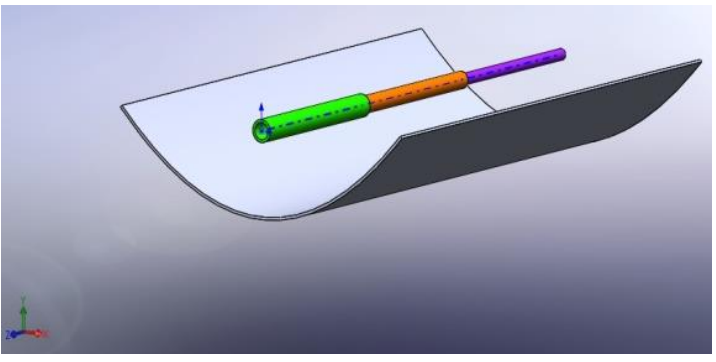

Figure 2. Solar system with stepped diameter receiver [14]

\section{MODELING AND MANUFACTURING OF A TAPERED RECEIVER USED IN SOLAR CYCLOIDAL CONCENTRATOR}

For modeling of a tapered receiver with solar cycloidal concentrator SOLIDWORKS software is used. The modeled view is as shown in Figure 3. In case of constant diameter as shown in Figure 1, constant concentration ratio is used where there are thermal losses and decrease in efficiency. In case of stepped diameter as shown in Figure 2, due to sudden change in receiver tube, thermal losses and heat losses are observed. Considering the facts in both these cases, a novel concept of tapered receiver as shown in Figure 3 is proposed and the authors have applied for a patent which is published.

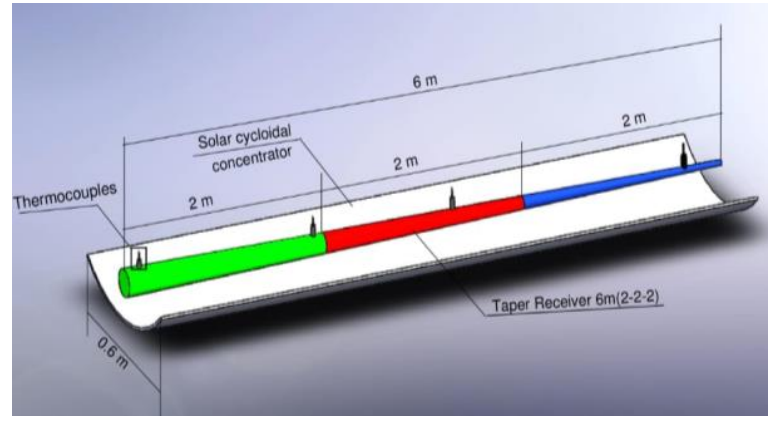

Figure 3. Solar system with tapered receiver [17]

This tapered receiver is used in solar cycloidal concentrating system as shown in Figure 4. For this solar concentrating system, concentrator length is used as $6 \mathrm{~m}$ and aperture width is used as $0.6 \mathrm{~m}$. Line of focus is at $0.375 \mathrm{~m}$ as shown in Figure 4. The thermal energy gained by the working fluid can be utilized for different applications in food industry, paper industry, textile industry and dairy applications. Analytical approach has been done for this solar system using various expressions. Expression for the balance of energy is used for the elaboration of proposed solar system.

Mathematically, Ratio of concentration is,

$$
\mathrm{CR}=\frac{\text { Aperature Area }}{\text { Incident Area }}
$$

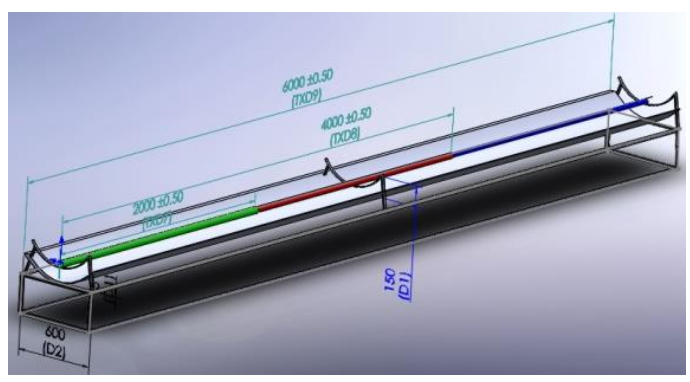

(a) Modeled view of set up [16]

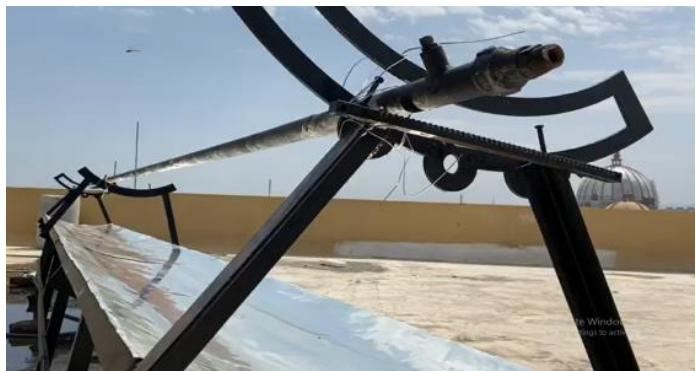

(b) Tapered receiver with solar cycloidal concentrator

Figure 4. Actual experimental set up

\subsection{Manufacturing of tapered receiver}

Receiver tube is prepared from solid Stainless steel rod of 6 $\mathrm{m}$ with black coating. For the ease of manufacturing, entire rod is cut into three different sections having length of $2 \mathrm{~m}$ each. Operation of taper turning was done on each section such that diameter decreases from inlet to outlet steadily. All the sections drilled properly. Each section is then connected with each other by welding operation. Now receiver tube has become ready with higher diameter initial side and smaller at exit side as shown in Figure 3. The thermocouples used are of PT 100 the range of this particular thermocouple is from 0 to 
$275^{\circ} \mathrm{C}$. The thermocouple is calibrated in order to get the correct readings and avoid the error. In addition to the temperature measurement of the water along the length of pipe, temperature is measured at the inlet and outlet of the receiver. In order to mount the thermocouples; small holes are drilled into the pipe. The legs of thermocouples are placed in these holes and the holes are sealed by sealing agent.

\subsection{Solar flux distribution}

In the proposed solar cycloidal thermal concentrating system with tapered receiver, the concentrator was used having the dimensions as $6 \mathrm{~m}$ in length and $0.6 \mathrm{~m}$ in width as shown in Figure 4. The variation in the rim angle causes variation in the focus of the reflected rays. After this focus starts getting enlarged. In this research, as author intent to use a south orient E-W cycloidal concentrator, the movement of the sun from N-S is $47^{\circ}$, hence the rim angle is selected as $23.5^{\circ}$. Thus, the arc or sector of the circle subtends as angle of $47^{\circ}$ at its center. As the latitude of the location changes the position of the sun also changes equal to the latitude. During the year the sun undergoes a simple harmonic motion through an angle of $46.9^{\circ}$ (approximately $47^{\circ}$ ) north to south position. This motion is an important criterion while using east-west oriented concentrator. Hence, the concentrator has made considering the sun's motion so that arc of the concentrator becomes cycloidal having an inclination of $47^{\circ}$. The concentrator reflects the solar energy incident on it into heat energy. The tapered receiver is fixed along a line of focus of cycloidal concentrator. The fluid was flowing through this receiver. This reflected heat energy was absorbed by the tapered receiver. The calibrated pyranometer was used to measure the radiations reflected by the cycloidal concentrator towards tapered receiver. Figure 5 shows total distribution of solar incident energy on cycloidal concentrator and represents reflection of the radiations or energy per unit length reflected along a line of focus.

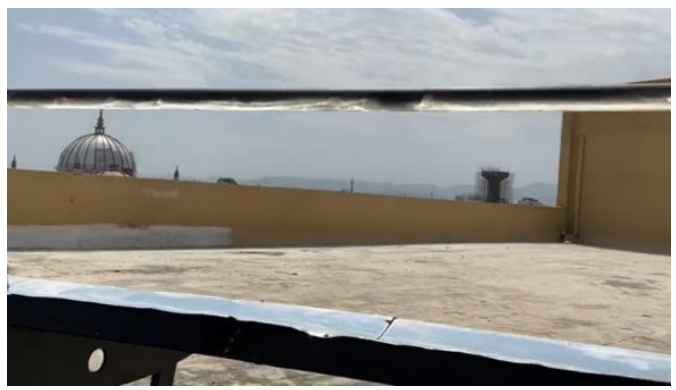

Figure 5. Solar flux distribution on receiver pipe

Optical efficiency of reflector is directly proportional to the concentrating system performance; hence reflector plays very important role in it. The optical efficiency of solar circular line concentrating system is given by,

$$
\eta=\rho \alpha \Upsilon
$$

where,

$\rho$ is the reflectivity of the reflector surface, $\alpha$ is the Absorptivity of the receiver, $\boldsymbol{Y}$ is the Intercept factor. The value of intercept factor, the most complex parameter involved, play important role in determining the optical efficiency of a line concentrator. It is a constant and depends on the size of the receiver, the surface angle errors of the reflector and solar beam spread.

From above equation, it is clear that the efficiency is directly proportional to the reflectivity and absorptivity, hence its magnitude is high. In the present case, the surface having reflectivity 0.95 is used. The efficiency of this solar system with tapered receiver is given by following equation,

$$
\eta=\frac{\mathrm{m}_{\mathrm{w}} \mathrm{C}_{\mathrm{p}}(\mathrm{T} 2-\mathrm{T} 1)}{\mathrm{I}_{\mathrm{b}} *(\mathrm{~A}-\mathrm{Ar})}
$$

\subsection{Solar cycloidal concentrator with energy balance}

For the solar cycloidal system, balance of energy is as shown in Figure 6. This figure shows solar flux distribution into fruitful heat gain, loss of heat and ocular losses. Solar meter is used to calculate the amount of solar energy incident on line of focus and factor of interlope is also calculated [15].

$$
\text { Energyacrosstheaperture } \mathrm{E}_{\mathrm{A}}=\mathrm{I}_{\mathrm{b}} \cdot \mathrm{A}
$$

Energy reflected by the solar concentrating system is the expressed as Eq. (5) which is multiplication of radiated beam and reflectivity.

Energy reflected by the concentrator $E_{R}=I_{b}$. A. $\rho$

The sun meter is used for the measurement of incident solar beams. Energy intercepted by receiver tube is given by,

$$
\mathrm{I}_{\mathrm{b}}(\text { by receiver })=\mathrm{I}_{\mathrm{b}} \mathrm{A} \rho \alpha \Upsilon
$$

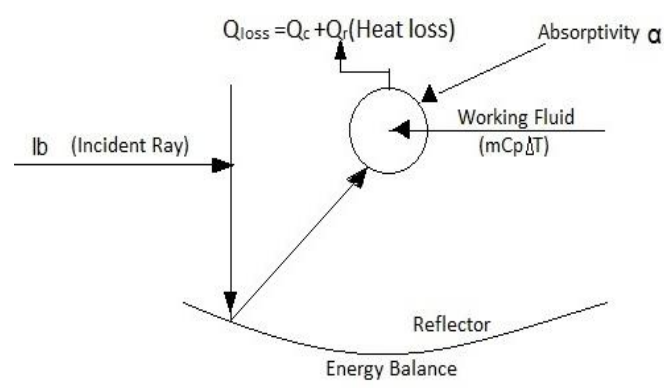

Figure 6. Energy balance of cycloidal concentrator [8]

Energy balance equation for the solar cycloidal concentrating system with tapered receiver for the required heat gain is expressed as,

$$
\mathrm{m}_{\mathrm{w}} \mathrm{C}_{\mathrm{P}} \Delta \mathrm{T} 1=\mathrm{I}_{\mathrm{b}} \mathrm{A} \rho \alpha \mathrm{Y}-\left(\mathrm{Q}_{\mathrm{C}}+\mathrm{Q}_{\mathrm{r}}\right)
$$

\section{GOVERNING EQUATIONS}

Loss of heat due to convection is expressed as,

$$
\mathrm{Q}_{\mathrm{C}}=\mathrm{h}_{\mathrm{c}} \Pi \mathrm{dL}\left(\mathrm{T}_{\mathrm{r}}-\mathrm{Ta}\right)
$$

The radiation heat loss $\mathrm{Qr}_{\mathrm{r}}$ is calculated by using the equation,

$$
\mathrm{Q}_{\mathrm{r}}=€ \sigma \Pi \mathrm{d} \mathrm{L}\left(\mathrm{T}_{\mathrm{r}}^{4}-\mathrm{T}_{\mathrm{sky}}{ }^{4}\right)
$$


The convective heat transfer coefficient $\left(h_{c}\right)$ for outside surface of the receiver is calculated by using standard correlation as,

$$
\mathrm{h}_{\mathrm{c}}=\frac{\mathrm{N}_{\mathrm{u}}}{\mathrm{L}}
$$

$\mathrm{N}_{\mathrm{u}}$ is the Nusselt number and expressed as,

$$
\mathrm{Nu}=\left\{0.60+0.387 \mathrm{R}_{\mathrm{a}} \frac{1}{6}\left[1+\left[\frac{0.559}{\mathrm{P}_{\mathrm{r}}}\right]^{\frac{9}{16}}\right]^{\frac{-8}{27}}\right\}^{2}
$$

where, $\mathrm{R}_{\mathrm{a}}$ Rayleigh number and $\mathrm{P}_{\mathrm{r}}$ is the Prandtl number.

$$
R_{\mathrm{a}}=\mathrm{G}_{\mathrm{r}} \cdot \mathrm{P}_{\mathrm{r}}
$$

Using above equations of Nusselt number and Rayleigh number with varying receiver temperature, heat loss due to convection and radiation for theoretical performance is calculated. These co-relations are taken from previously published literature [8].

The Grashof number is calculated as,

$$
\mathrm{Gr}=\frac{\mathrm{L}^{3} \mathrm{~g}_{\mathrm{c}} \beta \Delta \mathrm{T}}{\vartheta^{2}}
$$

\section{GEOMETRY AND MESH GENERATION}

Geometry is made with the help of modeling software and the details of the geometry are as per the actual setup. The position of receiver tube from solar concentrator is at $0.375 \mathrm{~m}$ for achieving desired line of focus. Receiver tube is having length of $6 \mathrm{~m}$. The solar concentrator is also having length of $6 \mathrm{~m}$. Before finalizing the size of receiver as tapered receiver, experiments were conducted using three constant diameter receivers. The diameter of third receiver is lesser than second and diameter of second is lesser than first. The results show as diameter decreases concentration ratio increases, intercept factor decreases leading to reduction in heat losses which increases the efficiency. Considering these results, a novel concept of tapered receiver is proposed and used in the present work. Related results are published in research articles [16].

Inlet part of the tapered tube is having radius $0.029 \mathrm{~m}$ and the outlet part of the tapered tube is of radius $0.010 \mathrm{~m}$. After completion of the geometry it is exported to the analysis software. Figure 7 shows modeling of tapered receiver tube.

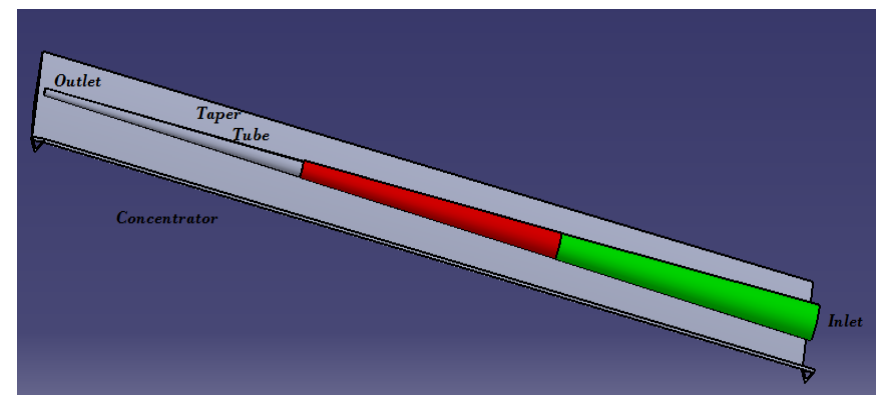

Figure 7. Modeling of concentrator and tapered pipe with various sections
ANSYS FLUENT is used for geometry design and mesh generation. To minimize load of the computation, mesh size and progression selected which is in optimized manner for desired accuracy. To model a solid-fluid domain, the blocking strategy is used. Solid Pipe Cross section meshing is as shown in Figure 8. The technique allows handling each block separately. This therefore makes it possible to minimize the number of cells. The first block represents the solid domain (tube). Second block represent the fluid domain (water). Total numbers of the element in the meshing are 578612 and total nodes are 634320. Outer Solid pipe is represented in Figure 9. At the centre of the receiver coarse meshing is done as very less heat transfer property change occurs at centre. This fluid flow cross section meshing is shown in Figure 10. Fine meshing is required at the walls of the receiver and shown in Figure 11. For the optimum number of meshing, hexahedral mesh with above strategy is used to reduce number of the elements. To reduce the calculation time and obtain better accuracy, it is advisable to reduce number of mesh elements by applying fine mesh where actual heat transfer takes place and coarse mesh at portion which can be neglected because of less variation.

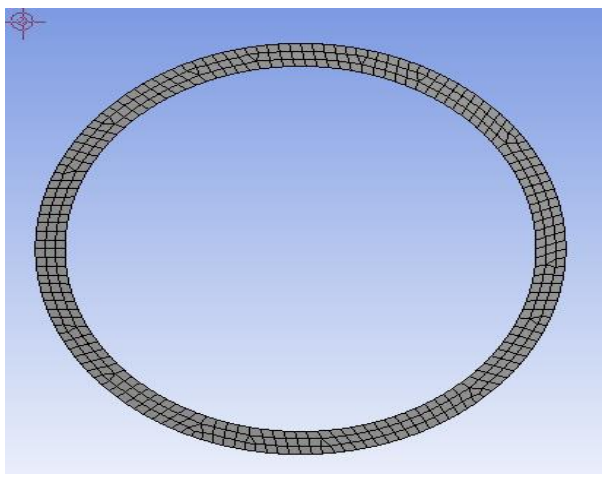

Figure 8. Solid pipe cross section meshing view

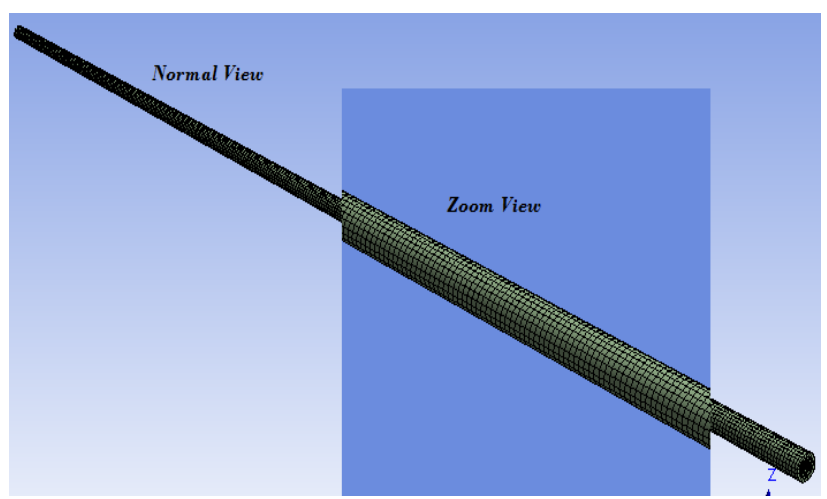

Figure 9. Outer solid pipe full view

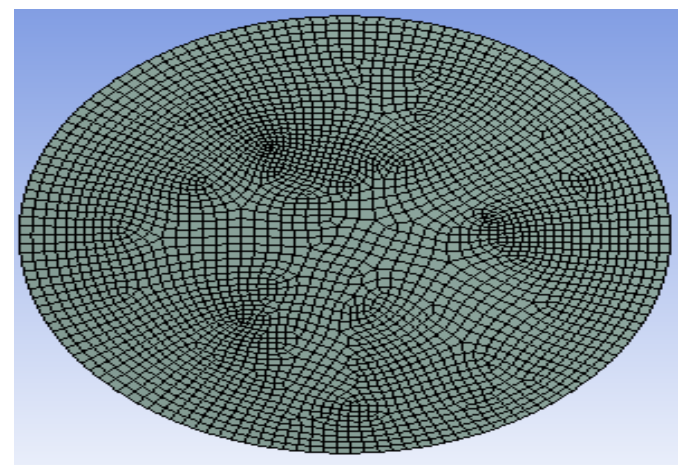

Figure 10. Fluid flow cross section meshing view 


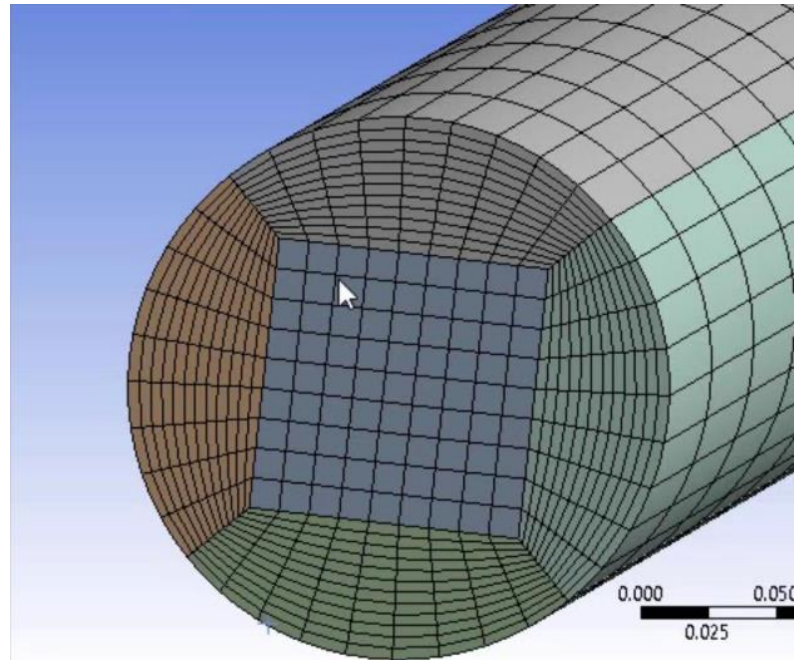

Figure 11. Strategy for optimal number of meshing

\section{MATERIAL PROPERTIES}

Material used for the solver is same as the actual material, Stainless steel with black coating and water as a working fluid medium. Stainless steel properties are already predefined in the fluent database. For the water as a fluid having temperature range 0 to $150^{\circ} \mathrm{C}$, the below mentioned equations can used with a simple formula without any significant loss of accuracy [18]. In order to implement fluid properties in the solver we use interpolation functions. Accordingly, these properties are described by the following equations,

$$
\text { Density }(\rho)=a+b T+c T^{2}+d^{2.5}+e T^{3}
$$

where, $\mathrm{a}=999.7968, \mathrm{~b}=0.06831, \mathrm{c}=-0.0107402$, $\mathrm{d}=0.0008214, \mathrm{e}=-2.3030 * 10^{-5}$ are constants.

$$
\text { Thermal conductivity }(\lambda)=a+b T^{1.5}+d T^{2}+e T^{0.5}
$$

where, $\mathrm{a}=0.5650, \mathrm{~b}=0.00263, \mathrm{c}=-0.0001251$, $\mathrm{d}=-1.5154 \mathrm{X} 10-6$, and $\mathrm{e}=-0.0009412$ are constants.

$$
\text { Specific heat capacity }\left(C_{p}\right)=a+b T+c T^{1.5}+d^{2}+e T^{2.5}
$$

where, $\mathrm{a}=4.2174, \mathrm{~b}=-0.005618, \mathrm{c}=0.001299, \mathrm{~d}=-0.0001153$, and $\mathrm{e}=4.14964 \times 10^{-6}$ are constants.

$$
\operatorname{Viscosity~}(\mu)=1 /\left(a+b T+c T^{2}+d T^{3}\right)
$$

where, $\mathrm{a}=557.8246, \mathrm{~b}=19.4087, \mathrm{c}=0.1360$, and $\mathrm{d}=-3.1160 \times 10-4$ are constants.

Note that these expressions are valid only for the temperature range $[0-150]{ }^{\circ} \mathrm{C}$. This temperature range is sufficient for solar heat exchange without change of liquid phase. The previous property equations are implemented in the solver as micros expressions for the fluent solver.

\section{INITIALIZATION AND BOUNDARY CONDITIONS}

Before starting the solver, boundary condition settings play vital role in CFD problem. Initially when time $t=0 \mathrm{~s}$, it is assumed that the fluid and the solid are at the same temperature
$\mathrm{T}^{0}$; the fluid velocity and pressure are set to zero.

For inlet boundary condition mass flow inlet is chosen and initial pressure is kept as atmospheric pressure so that the fluid boiling point must not be reached. At the tube outlet, a pressure outlet is applied. The pressure value at this location is to be observed so that the pressure drop ensures a non-high fluid velocity. The mass flow rate for the analysis is obtained from the experimental study. This mass flow input, pressure output and wall boundary conditions are represented in Figure 12. Wall boundary condition is used to make a separation between fluid and solid region of the tapered tube. At wall, no slip condition is assumed. Coupled condition is defined at the interference of water and tube so that heat transfer from tube to water is possible. On the external surface of the tube, a heat flux is distributed. Heat flux quantity is varying according to the location.

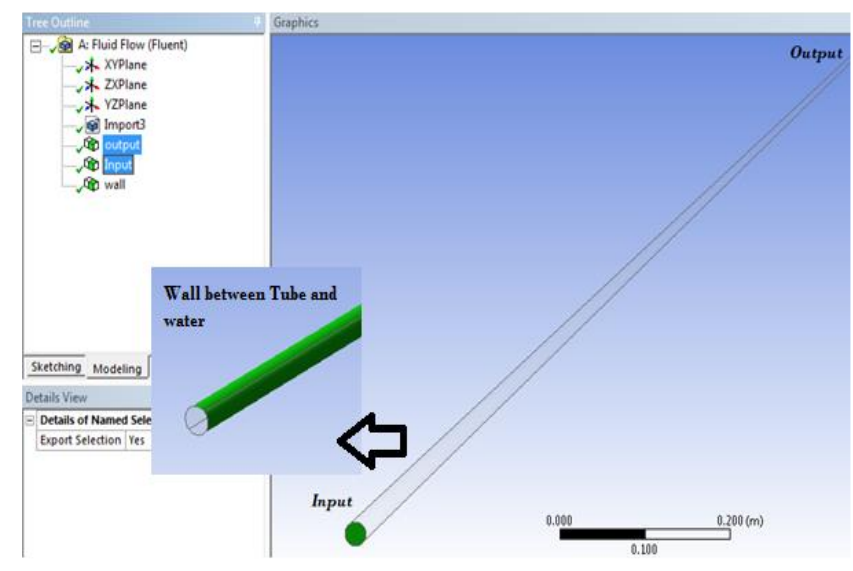

Figure 12. Mass flow input, Pressure output and wall boundary conditions

Initialization of the solver is done with hybrid approach and with slow increment in the heat flux amount application which means to find the probable accurate solution from the set of non-dominated solutions. This is done to get more accuracy and steady nature of the results.

\section{SOLVER SET UP}

ANSYS FLUENT is used to solve the mathematical model for solid-fluid domain. This software uses a method called element-based finite volume to discretize the conjugate heat transfer and fluid flow equations. Energy model is selected to have energy transfer between solid and fluid. Pressure based steady time and absolute velocity solver is selected. K-epsilon standard 2 equitation's model is preferred for this type of the problems [19]. Scalable wall function and standard Prandtl number is used for the calculations. Discrete transfer model of radiation with all standard parameters is selected. The heat flux boundary conditions are introduced with variable parameter. The time step is set to $5 \mathrm{~min}$, the calculation time is varying according to accuracy. Calculation accuracy is set to $10^{-3}$ in terms of Root Mean Square Error (RMSE). All convergence parameters are taken up to $10^{-3}$ accuracy of RMSE. For pressure velocity coupling, SIMPLE algorithm is used with second order upwind momentum and energy spatial discretization. Least square cell-based gradient is taken for solving method. Standards under relaxation factors are used for the calculation. 


\section{RESULTS AND DISCUSSIONS}

This section presents the heat flux and temperature distributions over the absorber tube and collector efficiency at different operating conditions. The results and discussions are representation of actual site readings and simulation on the computational fluid dynamics software.

\subsection{Solar radiation}

The experimentation performed in the first four months of 2020 that is from the month of January and April. Later, simulation is carried away to generate probable outputs, which are discussed here in further sections. The solar contributions are given for the actual site location. The concentrations of solar radiations are measured using the solar cycloidal concentrator and sun meter. Graphical representation below shows the solar radiation as a function of time for average temperature taken for the month of January and April as a function of time.

From this it is observed that minimum beam radiation is in the morning 8:00 am and the value of the beam radiation is around $580\left(\mathrm{~W} / \mathrm{m}^{2}\right)$ in the month of January and maximum solar beam radiation is observed in the month of April at 13:00 with value of $1160\left(\mathrm{~W} / \mathrm{m}^{2}\right)$. The readings are tabulated which are recorded during actual experimentation and represented graphically in Figure 13. Table 1 represents the reading for heat flux measurement.

Table 1. Heat flux measurement

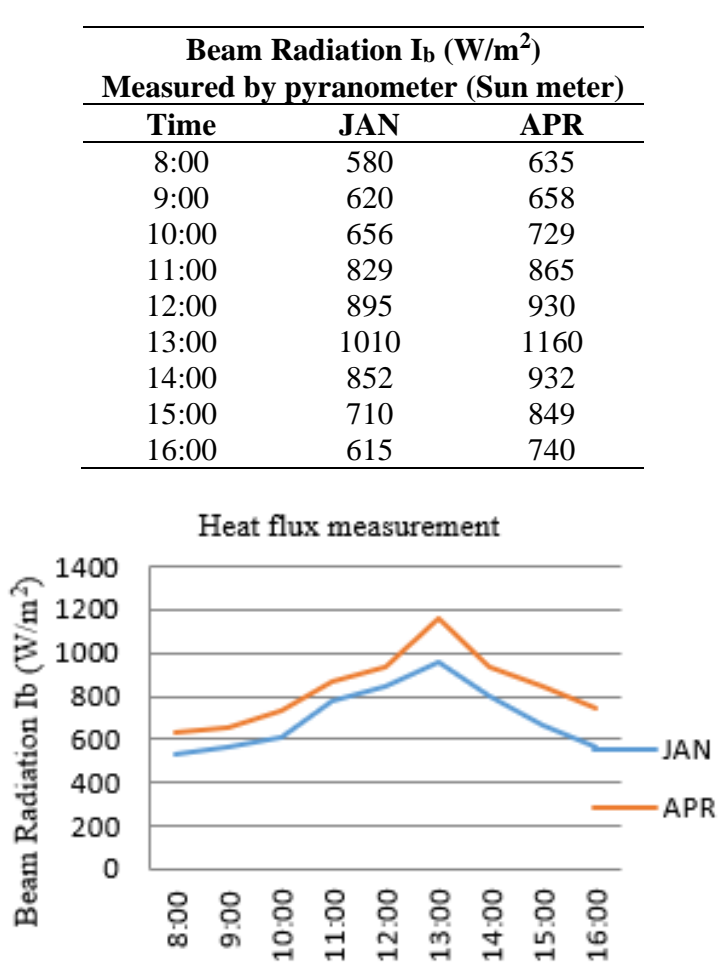

Figure 13. Heat flux measurement of solar radiation

\subsection{Fluid outlet temperature}

The temperature is recorded at the entry of the tapered tube and the exit of the tapered tube. The variations of the temperature, at the tube inlet and outlet, at different days are represented in Figure 14 with respect to time. For the purpose of simulation using the software to find out output temperature, required input temperature data is taken from the real time observations during the month of January and March and for the remaining two months, data required is taken from the Pune city temperature trends [20]. The fluid temperature at the outlet of the absorber tube is directly proportional to the direct sunlight, and it mainly depends on the heat quantity absorbed by the tube, which is based on optical and geometric parameters of the concentrator. We observed that the maximum temperature which is achieved with the help of setup is $81.4^{\circ} \mathrm{C}$ in the month of April while value of temperature gain curve which is obtained for January month is $24.94^{\circ} \mathrm{C}$, which is less as compared with value obtained in April. In the same way, the maximum temperature differences obtained are $43.59^{\circ} \mathrm{C}$ in April and $13.3^{\circ} \mathrm{C}$ in January.

Following Table 2 gives details about temperature difference observed in the simulation with respect to time.

Table 2. Fluid outlet temperature

\begin{tabular}{ccccc}
\hline \multicolumn{4}{c}{ Average Difference in Outlet temperature ${ }^{\circ} \mathbf{C}$} \\
\hline Time & JAN & APR & JUL & OCT \\
\hline $8: 00$ & 14.49 & 24.27 & 26.45 & 22.89 \\
$9: 00$ & 17.67 & 27.29 & 27.22 & 24.96 \\
$10: 00$ & 20.85 & 30.32 & 27.98 & 27.03 \\
$11: 00$ & 24.04 & 33.35 & 28.75 & 29.10 \\
$12: 00$ & 29.38 & 38.47 & 30.53 & 32.78 \\
$13: 00$ & 34.73 & 43.59 & 32.32 & 36.46 \\
$14: 00$ & 32.06 & 41.03 & 31.42 & 34.62 \\
$15: 00$ & 29.38 & 38.47 & 30.53 & 32.78 \\
$16: 00$ & 26.71 & 35.91 & 29.64 & 30.94 \\
\hline
\end{tabular}

\section{Fluid Outlet Temperature}

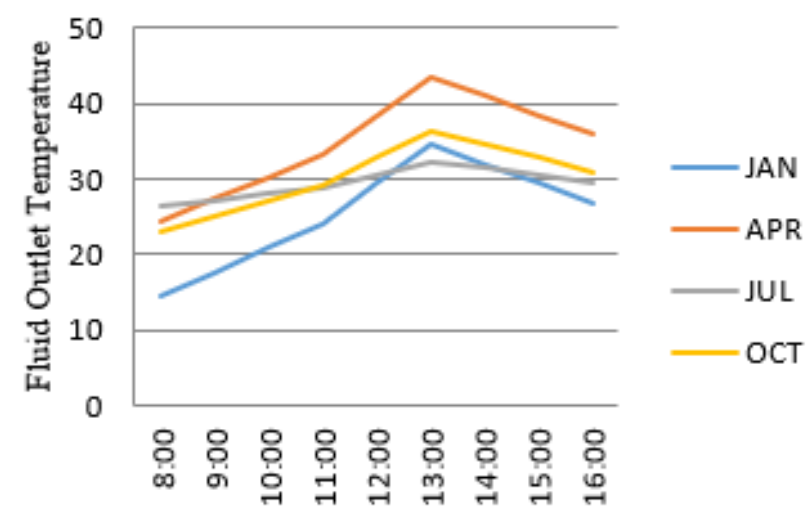

Figure 14. Fluid outlet temperature

\subsection{Useful thermal energy}

Water is used as heat carrier fluid. The average mass flow rate of the fluid through the absorber tube is $0.005[\mathrm{~kg} / \mathrm{s}]$, outlet pressure was kept as atmospheric pressure and same conditions are applied for the simulation. During the simulation, the physical properties of the heat carrier fluid are varied depending on the temperature of the fluid according to equations shown in the material section above.

It is noticed that the variation profiles are like those of the temperature at the tube outlet. We also note that the heat gain is maximum in the afternoon, between $12: 00$ to $14: 00 \mathrm{hr}$, in the month of April. Heat is minimum in the morning and evening in the month of January. Maximum heat gain is $31.1681 \mathrm{~W}$ and minimum heat gain is $10.363 \mathrm{~W}$. Useful thermal gain is represented as shown in Figure 15. The reading for the useful thermal gain is represented in Table 3. 
Table 3. Useful thermal energy

\begin{tabular}{ccccc}
\hline \multicolumn{5}{c}{ Solar Heat Gain $(\mathbf{W})$} \\
\hline TIME & JAN & APR & JUL & OCT \\
\hline $8: 00$ & 10.363 & 17.3527 & 18.9148 & 16.3651 \\
9:00 & 12.6372 & 19.5185 & 19.4628 & 17.8451 \\
$10: 00$ & 14.9115 & 21.6814 & 20.0109 & 19.3251 \\
$11: 00$ & 17.1886 & 23.8472 & 20.5589 & 20.8051 \\
$12: 00$ & 21.0103 & 27.5076 & 21.8338 & 23.4369 \\
$13: 00$ & 24.8348 & 31.1681 & 23.1086 & 26.0687 \\
$14: 00$ & 22.924 & 29.3364 & 22.4698 & 24.7528 \\
$15: 00$ & 21.0103 & 27.5076 & 21.8338 & 23.4369 \\
$16: 00$ & 19.0994 & 25.6789 & 21.1949 & 22.121 \\
\hline
\end{tabular}

Solar Heat Gain (W)

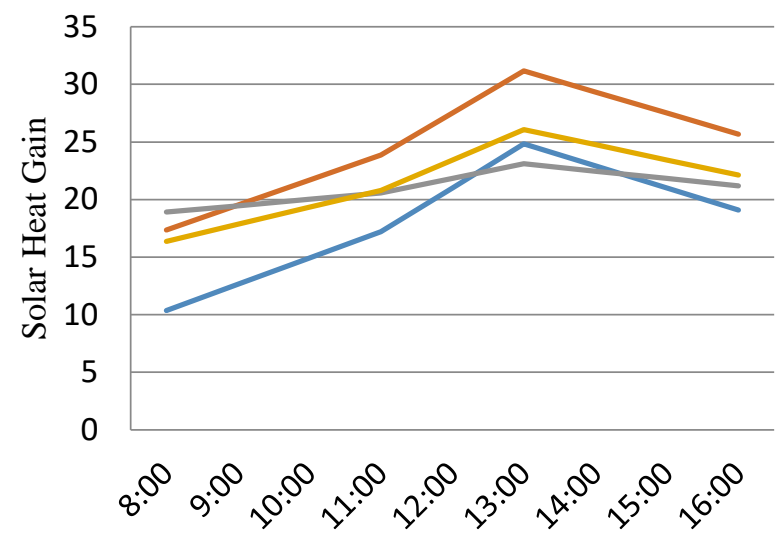

Figure 15. Useful thermal gain

\subsection{Thermal efficiency}

The thermal efficiency values obtained by numerical simulation are shown below. The experimentation performed from Jan to April and observations are noted throughout the month. Efficiency is calculated by,

$$
\eta_{\exp }=\left[\mathrm{m}_{\mathrm{w}} \mathrm{C}_{\mathrm{p}}\left(\mathrm{T}_{2}-\mathrm{T}_{1}\right)\right] / \mathrm{I}_{\mathrm{b}}\left(\mathrm{A}-\mathrm{A}_{\mathrm{r}}\right)
$$

As it can be seen, the efficiency is inversely proportional to the temperature difference. Thermal efficiency is shown in Figure 16. Efficiency is nearly constant thought the day in January and is around $24 \%$ and also, in April efficiency obtained is $34 \%$. This efficiency is compared with constant diameter receiver and found that there is improvement of $10 \%$ in thermal efficiency. The values of thermal efficiency are tabulated in Table 4. This is published separately [16].

\section{Efficiency}

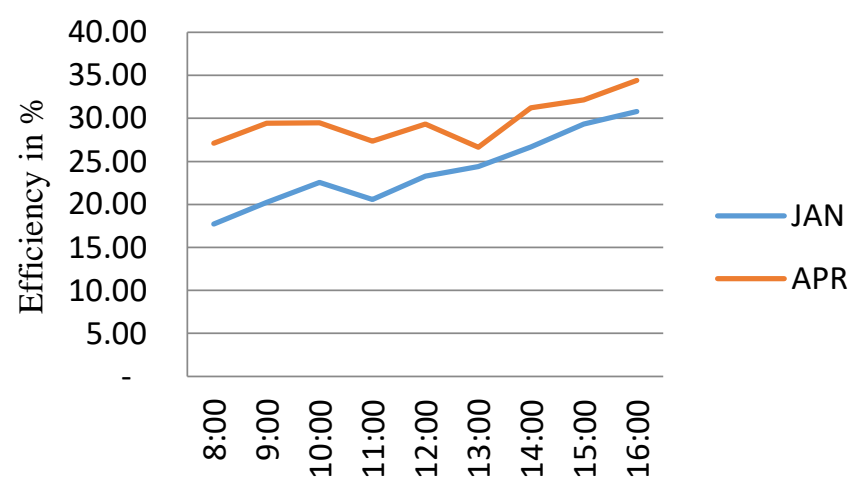

Figure 16. Thermal efficiency
Table 4. Thermal efficiency

\begin{tabular}{ccc}
\hline \multicolumn{3}{c}{ Efficiency (\%) } \\
\hline Time & JAN & APR \\
\hline $8: 00$ & 17.72 & 27.10 \\
$9: 00$ & 20.21 & 29.41 \\
$10: 00$ & 22.54 & 29.49 \\
$11: 00$ & 20.56 & 27.34 \\
$12: 00$ & 23.28 & 29.33 \\
$13: 00$ & 24.38 & 26.64 \\
$14: 00$ & 26.68 & 31.21 \\
$15: 00$ & 29.35 & 32.13 \\
$16: 00$ & 30.80 & 34.41 \\
\hline
\end{tabular}

\section{CONCLUSION}

Modeling, simulation and analysis of the of tapered receiver utilization in solar cycloidal concentrating system for enhancement of system efficiency is carried out. Modeling of the tapered receiver tube, which is novelty of this research, is done using of SOLIDWORKS software. The governing equations of fluid flow and heat transfer in the system are solved by using ANSYS-CFX CFD software. Results obtained using simulation show enhancement in efficiency and temperature increment also. Experimental results and analysis using software shows noticeable decrement in thermal losses as there is decrement in the area from inlet to outlet of receiver tube and hence increase in the efficiency is observed. The results obtained during experimentation and numerically are found in good agreement. Solar radiations, fluid outlet temperature, useful heat gain or useful thermal energy and thermal efficiency are analysed. Solar beam radiation is found minimum at the morning 8:00 am and the value of the beam radiation is around $580\left(\mathrm{~W} / \mathrm{m}^{2}\right)$ in the month of January and maximum solar beam radiation is observed in the month of April at 13:00 with value of $1160\left(\mathrm{~W} / \mathrm{m}^{2}\right)$. Accordingly, Maximum fluid temperature achieved is $81.4^{\circ} \mathrm{C}$ in the month of April while minimum temperature gain is obtained for January, which gives minimum temperature of $24.94^{\circ} \mathrm{C}$. Similarly, the temperature difference obtained is maximum $43.59^{\circ} \mathrm{C}$ in April and $13.3^{\circ} \mathrm{C}$ in January. With constant receiver outlet temperature is $68^{\circ} \mathrm{C}$. Hence after comparison it is found that difference between maximum fluid temperature achieved for taper receiver which is $81.4^{\circ} \mathrm{C}$ and in case of constant diameter receiver which is $68^{\circ} \mathrm{C}$, is $\left(81.4^{\circ} \mathrm{C}-68^{\circ} \mathrm{C}=13.4^{\circ} \mathrm{C}\right)$. It is observed that maximum thermal gain is $31.1681 \mathrm{~W}$ and minimum heat gain is $10.363 \mathrm{~W}$ which is more as compared with constant diameter receiver by $20 \mathrm{~W}$.In case of thermal efficiency maximum thermal efficiency obtained is $34 \%$ which is $10 \%$ more than the efficiency obtained in case of constant diameter receiver. The energy intercepted depends upon the concentration ratio as the concentration increases the intercept factor decreases. However, as concentration ratio increases, the receiver diameter decreases and the heat loss per unit area length of receiver decrease. Thus, for any solar thermal system having high temperature difference, using a single concentration ratio (constant diameter receiver, used by researchers in previous research) cannot offer optimum performance. Thus, it is necessary to optimize the concentration ratio for a solar thermal system, depending upon the temperature of fluid. For a system having higher temperature difference, a variable concentration ratio using taper receiver would be more appropriate. 


\section{REFERENCES}

[1] Sukki, F.M. (2011). A review on solar concentrator. International Journal of Applied Sciences (IJAS), 1(1): $1-15$.

https://www.cscjournals.org/manuscript/Journals/IJAS/ Volume1/Issue1/IJAS-8.pdf.

[2] Padilla, R.V., Demirkaya, G., Yogi Goswami, D., Stefanakos, E., Rahman, M.M. (2011). Heat transfer analysis of parabolic trough solar receiver. Applied Energy. $\quad 88(12)$ : $\quad 5097-5110$. http://dx.doi.org/:10.1016/j.apenergy.2011.07.012

[3] Meng, X.L., Sellami, N., Knox, A.R., Montecucco, A., Siviter, J., Mullen, P., Asraf, A., Samrelli, A., Llin, L.F., Paul, D.J., Li, W.G., Paul, M.C., Gregory, D.H., Han, G., Gao, M., Sweet, T., Freer, R., Azough, F., Lowndes, R., Xia, X.L., Mallick, T.K. (2016). A novel absorptive / reflective solar concentrator for heat and electricity generation; an optical and thermal analysis. Energy Conversion and Management, 114: 142-153. http://dx.doi.org/10.1016/j.enconman.2016.02.011

[4] Horta, P., Osorio, T. (2014). Optical characterization parameters for line focusing solar concentrators: measurement procedures and extended simulation results. Elsevier Energy Procedia, 49: 98-108. http://doi.org/10.1016/j.egypro.2014.03.011

[5] Lof, G.O., Fester, D.A., Duffie, J.A. (1962). Energy balances on a parabolic cylinder solar collector. J. Eng. Gas Turbines Power, 84(1): 24-32. http://doi.org/10.1115/1.3673371

[6] Beucherie, P. (2015). Selective absorbent surfaces for high temperature solar collector. Electric Power System Research, 3(1-2): 125-137. https://doi.org/10.1016/03787796(80)90028-0

[7] Mahdib, K., Bellel, N. (2014). Development of a spherical solar collector with a cylindrical receiver. Energy Procedia, 52: 438-448. https://doi.org/10.1016/j.egypro.2014.07.096

[8] Kulkarni, C.N., Jahagirdar, R.S., Talib, M.I., Tasgaonkar, G.S. (2017). Enhancing performance of solar line concentrator system using variable Concentration ratio. ICAAMM-2016. Materials Today: Proceedings, 4(8): 7533-7545. https://doi.org/10.1016/j.matpr.2017.07.085

[9] Wirz, M., Roesle, M., Steinfeld, A. (2012). Three dimensional optical and thermal numerical model of solar tubular receivers in parabolic trough concentrators. Journal of Solar Energy Engineering, 134: 041012/1-9. https://doi.org/10.1115/ES2012-91154

[10] Lüpfert, E., Herrmann, U., Price, H., Zarza, E., Kistner, R. (2004). Towards standard performance analysis for parabolic trough collector fields. Solar Paces Conference. Mexico, Oaxaca Luepfert, pp. 22-71. http://researchgate.net/publication/312194398

[11] Caron, S., Roger, M. (2015). Modeling, simulation and identification of heat loss mechanisms for parabolic trough receivers installed in concentrated solar power plants. IFAC-Papers on Line, 48(1)372-377. https://doi.org/10.1016/j.ifacol.2015.05.058

[12] Chen, F. (2015). Distribution of energy density and optimization on the surface of the receiver for parabolic trough solar concentrator. International Journal of Photo Energy, 20 : https://doi.org/10.1155/2015/120917
[13] Stine, W.B., Geyer, M. (2011). A Book on Power from Sun. http://www.powerfromsun.net/book.html. Copyrights.

[14] Kulkarni, C.N., Tasgaonkar, G.S. (2015). Indian Patent no 88/MUM/2014. Indian patent Official Journal Issue No. 35/2015. http://ipindia.gov.in/journal-patent.htm

[15] Duffie, J.A., Beckman, W.A. (2016). A Book on Solar Engineering of Thermal Processes. 3rd Edition John Wiley \& Sons. https://doi 10.1002/9781118671603

[16] Kulkarni, M.M., Dingare, S.V., Kulkarni, C.N. (2020). Novel concept of utilizing geometrically taper receiver and solar cycloidal concentrator system for enhancing efficiency of solar concentrating system. In Press. https://doi.org/10.1016/j.matpr.2020.06.033

[17] Kulkarni, M., Dingare, S., Kulkarni, C. (2020). Indian Patent no. 202021028009A, Indian patent Official Journal Issue No. $31 / 2020$ dated 31/07/2020, A mechanism comprises taper receiver for solar cycloidal concentrator system http://www.ipindia.nic.in/writereaddata/Portal/IPOJourn al/1_4891_1/Part-1.pdf.

[18] Popiel, C.O., Wojtkowiak, J. (1998). Simple formulas for thermo physical properties of liquid water for heat transfer calculations (from $0^{\circ} \mathrm{C}$ to $150^{\circ} \mathrm{C}$ ). Heat Transfer Engineering, 19(3): 87-101. http://doi.org/10.1080/01457639808939929

[19] Shirzadi, M., Mirzaei, P.A., Naghashzadegan, M. (2017). Improvement of k-epsilon turbulence model for CFD simulation of atmospheric boundary layer around a highrise building using stochastic optimization and Monte Carlo Sampling technique. Journal of Wind Engineering and Industrial Aerodynamics, 171: 366-379. https://doi.org/10.1016/j.jweia.2017.10.005

[20] India Metrological Department, Ministry of Earth Sciences. http://www.imdpune.gov.in/.

\section{NOMENCLATURE}

$\mathrm{L}_{1} \quad$ Receiver tube perimeter $(\mathrm{m})$

$\mathrm{T}_{\text {in }} \mathrm{T}_{\text {out }} \quad$ Water temp.at initial and at end $(\mathrm{K})$

tr $\quad$ Receiver tube temperature $\left({ }^{\circ} \mathrm{C}\right)$

$\mathrm{T}_{\mathrm{r}} \quad$ Temperature of receiver $\operatorname{rod}(\mathrm{K})$

$\mathrm{t}_{\mathrm{a}} \quad$ Surrounding temp. $\left({ }^{\circ} \mathrm{C}\right)$

$\mathrm{T}_{\mathrm{m}} \quad$ Mean temperature (K)

$\Delta \mathrm{T} \quad$ Deviation in temp. $(\mathrm{Tr}-\mathrm{Ta})(\mathrm{K})$

$\mathrm{G}_{\mathrm{r}} \quad$ Grashoff number

$P_{r} \quad$ Prandtl number

$\mathrm{R}_{\mathrm{a}} \quad$ Rayleigh number

$\mathrm{N}_{\mathrm{u}} \quad$ Nusselt number

$\mathrm{K}$ Thermal conductivity $\left(\mathrm{W} / \mathrm{m}^{\circ} \mathrm{C}\right)$

$\mathrm{g}_{\mathrm{c}} \quad$ Gravitational acceleration $\left(\mathrm{m} / \mathrm{s}^{2}\right)$

$\mathrm{h}_{\mathrm{c}} \quad$ Coefficient of convective transfer $\left(\mathrm{W} / \mathrm{m}^{2 \circ} \mathrm{C}\right)$

L2 Length of concentrator (m)

Qc Convectional heat losses (W)

$\mathrm{T}_{\text {sky }} \quad$ Sky temp. (K)

Qr Heat loss due to radiation (W)

$\mathrm{I}_{\mathrm{b}} \quad$ Solar radiation incident $\left(\mathrm{W} / \mathrm{m}^{2}\right)$

$\mathrm{C}_{\mathrm{p}} \quad$ Specific heat at same pressure $\left(\mathrm{kJ} / \mathrm{kg} /{ }^{\circ} \mathrm{C}\right)$

$\mathrm{m}_{\mathrm{w}} \quad$ mass flow rate $(\mathrm{kg} / \mathrm{s})$

A Area of aperture $\left(\mathrm{m}^{2}\right)$

CR Concentration Ratio 


\section{Greek symbols}

P Reflectivity

$\alpha \quad$ Absorption

$\epsilon \quad$ Emittance capacity $\gamma \quad$ Factor of interlope

$\eta \quad$ Efficiency

$v \quad$ Fluid internal resistance $\left(\mathrm{m}^{2} / \mathrm{s}\right)$

$\beta \quad$ Thermal flow factor $(1 / \mathrm{K})$ 